\title{
The stimulus suffix: A paradoxical effect
}

\author{
DAVID SALTER and JOHN G. COLLEY \\ University of Newcastle, Newcastle-Upon-Tyne, England NE1 YRU, United Kingdom
}

\begin{abstract}
Two experiments are reported which showed that a stimulus suffix word, following eight words presented for immediate serial recall, affected recall performance differentially for the final list word: the target word. The observed difference depended on whether the target word and suffix were associated. It was concluded that both the target word and the redundant stimulus suffix were coded at the level of semantic coding as well as at the level of acoustic coding, and that an effect resulted where none had previously been found. There was no evidence to indicate that the coding of the semantic features required a switch in attention to the target word during the presentation of the list, and the coding for this was presumed to be autonomous. A model was described to explain the paradoxical effect of an associated stimulus suffix.
\end{abstract}

The stimulus suffix effect has been frequently reported in the literature. A review of this literature has been provided in a paper by Morton, Crowder, and Prussin (1971). Briefly described, the phenomenon is as follows. When lists of verbal items are presented for immediate serial recall, accuracy of recall is usually good over the first few serial positions, but, increasingly, errors occur over the remaining serial positions in the list. If presentation is auditory, rather than visual, the final items are also well recalled. The advantage which characterizes an acoustic signal disappears when the list is immediately followed by an extra redundant item which is not required in the recall response. The performance decrement of the final item in particular has been termed the "stimulus suffix effect."

Various explanations have been proposed to explain the underlying processes which cause the suffix effect. Kahneman (1973) has suggested that preattentive processes do not distinguish between the suffix and the presented list, but combine them to form one gestalt so that the suffix becomes an extra memory item even though it is not recalled. Massaro (1972) has argued that each item would have been identified at list presentation before the following item is presented, and that the suffix effect is therefore due to interference of subjects' short-term memory for the final items in the list. Yet a further explanation, which has gained a fair measure of acceptance, is that of Crowder and Morton (1969) and Morton (1970). They place the burden of the effect on the displacement of precategorical acoustic traces by the suffix information at a first stage in processing. Precategorical acoustic storage (PAS) reveals itself maximally when subjects are constrained to recall the stimuli in their order of presentation, where the contribution of PAS is large and consistent, as shown by both a comparison between visual-auditory presentation and in the effect of the suffix (Morton et al., 1971, p. 189).

A further proposal has been made (Glanzer, 1972; Morton, 1970) that the serial recall of items is also based upon secondary memory, assuming that attention is directed at each item in turn during presentation. This assumption of directed attention cannot be readily made about the last items in a supraspan list, however, when subjects are instructed to concentrate on the first items in serial recall. Given this instruction, it is feasible that the last item may be ignored completely, but retained nevertheless as precategorical acoustic information. (For the present discussion, this account excludes the possibility of automatic registration in secondary memory.) Storage at an acoustic level would explain why the stimulus suffix is so effective in displacing all trace of the final item, so that recall performance drops. This explanation appears to be one of the main conclusions of the extensive review by Morton et al. (1971), in which they stated that their experimental tests did not reveal any systematic differences in the size of the suffix effect that might be attributed to "intrinsic," as opposed to "extrinsic," properties of the suffix (p. 177), and that, in a large number of situations, the semantic properties of the stimulus suffix made no difference to the degree of performance failure occasioned by suffix presentation (p. 185). It is therefore unclear to what extent the final list word and the suffix are processed further than acoustic coding, and the question is open to empirical investigation. The present paper reports two experiments which tested the effect on last-item recall of changing the postcategorical attributes of a verbal stimulus suffix.

\section{EXPERIMENT 1}

\section{Method}

Subjects. Twelve undergraduates participated; all were unpaid volunteers from the University of Newcastle. The subjects were tested in groups of two or three persons at a time.

Materials and design. All the words used for the lists and suffixes were derived from Kučera and Francis (1967). They were monosyllables and mostly adjectives.

Seven groups of words were selected: Each group consisted of five words with approximately the same word frequency. 
From these groups, the first seven words in each list (termed the "base list") were generated. One word was chosen from each of the seven groups to construct each base list with the restriction that no particular word appeared in adjacent lists. The seven groups of stimulus words were equally distributed across the serial positions of the base lists in a block of 25 lists. Two such blocks comprised one series.

The eighth word of each list, which was termed the "target word," was chosen from a pool of 21 words. When the stimulus lists were presented, the target word was followed by an appropriate suffix word, which always had a different initial consonant. An appropriate suffix was either a synonym of the final list word or a synonym control which had virtually the same Kucera-Francis word frequency as that of the synonym suffix. Target words and suffixes were both monosyllabic and had the same grammatical classification; no word which appeared in the base lists was used as a target or a suffix. Four additional base lists were included for preliminary accommodation at the beginning of each block. The lists were followed by filler suffixes of a similar kind and were not scored.

Within a series, a particular target word was suffixed with a synonym in one block and with its equivalent synonym control in the second block. Target words appeared in the same list position relative to each block, so that a maximum number of lists (24 in this instance) intervened before the target word was repeated. The two types of suffix were mixed approximately equally across the two blocks with the constraint that no more than two synonyms or two synonym controls were presented consecutively.

A second series of stimulus lists were used in the experiment. The series contained two blocks of 25 lists with the same constraints as previously. New base lists were generated and the same target words were presented in reverse order to control for any target word-order effect. Six subjects were tested with each stimulus series. The order of blocks was counterbalanced within each series.

List items and suffixes were recorded in a female voice on magnetic tape with a Revox tape recorder, at a rate of one item per $.6 \mathrm{sec}$. One second before each list began, a tone of approximately $50-\mathrm{msec}$ duration sounded as a "Ready" signal. The same tone was also interposed between the target word and suffix to indicate the end of the list for recall, although the interstimulus interval between target word and suffix remained the same as that between all other adjacent words.

Procedure. On each trial, the subject heard a list of eight items followed by a suffix word. Following each list, approximately $15 \mathrm{sec}$ elapsed for written recall in the prepared response booklets. On each page, a row of eight boxes was printed, one box per serial position in the list. A separate block of eight practice lists was also recorded for preliminary trials. The more obvious characteristics of the lists were described in the instructions, where it was pointed out that the suffix was not part of the recall list. The recall procedure clearly specified that responses were to be made from the beginning of the list onward in serial order, without backtracking, and that an item was only scored correct if it was written in the proper box location. A visual check was maintained throughout the experiment to insure that the instructions were followed. Subjects were encouraged to guess rather than to leave a blank. Presentation was via headphones, so that external auditory distractions were eliminated. The experiment lasted approximately $35 \mathrm{~min}$, with a rest period of $5 \mathrm{~min}$ at the half-way stage.

\section{Results}

Questioned after the experiment, no subject appeared to be aware that target words had been repeated more than once across the two stimulus series. Responses to the first four lists in each block were discarded as accommodation lists. Recall data for the remaining lists

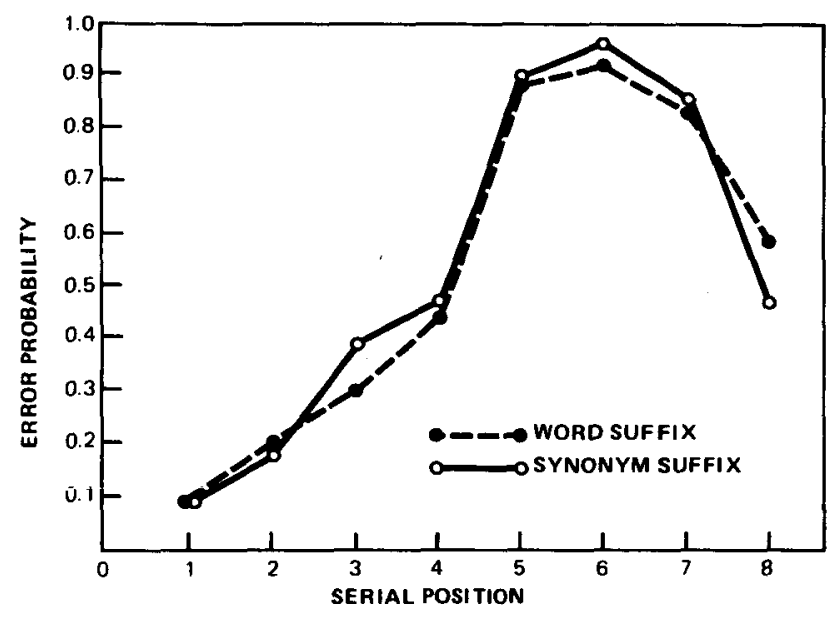

Figure 1. Serial position curves for immediate recall of eight-word lists as a function of a synonym association between the final list item and the stimulus suffix $\longrightarrow$ vs a control condition - - - $\bullet$.

were obtained by scoring an error against any response which did not match the stimulus word in each serial position.

Figure 1 depicts the recall error data plotted as serial position curves for lists in which the suffix was a synonym of the target word, compared with a control word suffix of similar word frequency. Each point was based upon 252 observations. The data were subjected to a three-factor analysis of variance, which tested across groups for differences between the stimulus list series, and within subjects for differences between suffix conditions, and between serial positions. Fixed effects were assumed. No reliable effects were obtained for list series, nor for the suffix conditions, on average. However, as the serial position curves indicated, reliable statistical results were obtained for serial positions $[F(7,70)=262.7, \mathrm{MSe}=4.39, \mathrm{p}<.001]$ and for the interaction of Serial Positions by Suffix Conditions $[F(7,70)=4.0, \quad M S e=2.14, \quad p<.001] . \quad$ Detailed comparisons at each point on the recall curves, using the Newman-Keuls procedure, located this interaction at Serial Position 3, where the synonym suffix condition showed poorer recall than the word suffix condition $(\mathrm{p}<.01)$, and at Serial Position 8 , where the synonym suffix condition was better recalled than the word suffix condition $(\mathrm{p}<.01)$.

\section{Discussion}

The target word in the list was recalled better when it was followed by a suffix which was a synonym rather than by a suffix which was a nonassociated word. The difference in recall indicated that both list word and suffix were being coded at a semantic level, although the subject was simultaneously following instructions to concentrate on remembering the items from the beginning of the list onward.

One obvious explanation of why the target word 
was better recalled was that the semantic association between the eighth item and the suffix had been noticed in passing. However, the recall data provided no evidence to indicate that subjects consistently used a guessing strategy for the synonym association. This would have become obvious in marking the responses for the synonym control condition. The data did provide some evidence that attention was directed at the target at the cost of the earlier items, because there was significantly poorer recall at Serial Position 3 in the synonym condition than at the same serial position in the nonassociated suffix lists.

To check on this possibility, the synonym association was tested in a second experiment to establish whether the divergence at Serial Position 3 remained as a consistent effect.

\section{EXPERIMENT 2}

\section{Method}

Subjects. Twenty subjects with an age range from 17-19 years participated. They were unpaid volunteers from local schools in the Newcastle area. Subjects were tested in groups of two or three at a time.

Materials. From Kučera and Francis (1967), a word pool was selected for lists and suffixes. The source words were not identical to the previous experiment, but were again monosyllabic and predominantly adjectives.

Seven groups of words were chosen for the base lists (Serial Positions 1-7, inclusive), five words to a group; the frequency ranges for the groups were as follows: (1) 2,216-686, (2) $665-275$, (3) $231-202$, (4) $179-109$, (5) $92-58$, (6) $55-35$, (7) $16-4$. The base lists were generated by randomly sampling each frequency group with the following constraints: Each word appeared an equal number of times over all lists; no two words in adjacent serial positions began with the same initial letter (this included target words and suffixes); no words with the same sounding syllable followed each other immediately; and, no word appeared in adjacent lists.

Design. An experimental series of stimulus lists consisted of two blocks with 35 lists per block. The first five lists in each block were preliminary lists and were not scored. The remaining 30 experimental lists were equally distributed between these three conditions: associated synonym suffix, nonassociated word suffix with the same frequency as the synonym suffix (see Appendix), and nonverbal suffix (a burst of white noise). Each target word in the last serial list position, Serial Position 8 , was paired with each suffix type. Identical base lists plus target words were presented with the synonym suffix or synonym control suffix in the same list positions in each stimulus block. A target word occurred a third time, paired with a noise suffix, and its list position was randomized within one of the blocks, with the constraint that at least 24 lists intervened before it was repeated. Target repetitions were counterbalanced relative to the experimental conditions across the two blocks of stimulus lists. Furthermore, no two synonym suffix lists were ever consecutive to reduce the chances of subjects noticing the association between the target word and the suffix.

The constraints also operated for a second series of stimulus lists. The serial position of the words within the base lists were generated in reverse order, as were their list positions in the block. Target words and their appropriate suffixes were reversed in order across blocks. Ten subjects received Series 1 , and 10 subjects received Series 2 . The order of block presentation was counterbalanced within each subject group.
Procedure. Ten practice lists preceded the experiment proper with dummy items. Four of these lists had the noise suffix, and six had word suffixes. All list items and suffixes were recorded in a male voice on a magnetic tape with a Revox tape recorder, at the rate of one item per $.6 \mathrm{sec}$. One second before each list began, a 50-msec tone sounded as a "Ready" signal. Just after the first word of the recall list had begun, a low continuous tone was introduced, which lasted until the end of the last word of the list, at Serial Position 8 . The level of the tone was clearly distinct from the word utterances and provided an unambiguous indication of the recall list; the suffix word was thus heard in isolation from the gestalt of the recall list. The interstimulus interval between the target word and the suffix was the same as between all other adjacent list words.

On each trial, the subject heard a list of eight words followed by the suffix, which was either a word or a burst of white noise. Subjects were instructed to recall as many of the list items as possible (i.e., those items accompanied by a low continuous tone), and to ignore the suffix. The instructions included the usual stipulations to recall the items in serial order with no backtracking, and to locate the items in their correct serial positions. A continuous visual check during the experiment insured that the instructions were followed. Subjects were encouraged to guess a word if they were in doubt.

The stimulus lists were heard through headphones, and responses were written in prepared booklets, one new page per list. The next list was presented when all subjects had finished responding to the previous list. A 5-min break separated the two blocks of 35 lists.

\section{Results}

Responses to the first five accommodation lists in each block were discarded. Recall data were based on the remaining 30 lists in each block. Error scores were tabulated for any responses which did not match the presented stimulus word in the correct location. The mean error probabilities are plotted in Figure 2.

Wilcoxon tests confirmed that both conditions with a word suffix showed poorer recall of the target item at Serial Position $8 \quad(p<.001)$, compared with a burst

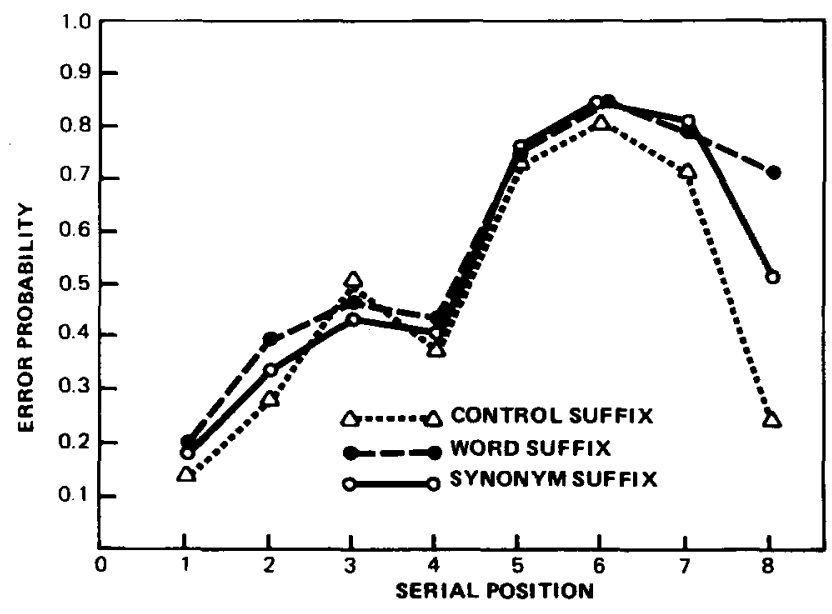

Figure 2. Serial position curves for immediate recall of eightword lists as a function of synonym association between the final list item and the stimulus suffix $\longrightarrow$, compared with two control conditions with a control word suffix - $--\bullet$, and a noise suffix $\cdots . . . \Delta$. 
of noise of the same length and duration as the suffix word. Interference caused by a verbal suffix was reduced $(p<.001)$ when the suffix and target words were synonyms compared with a word suffix condition in which there was no semantic association between the two words.

Analysis of variance was carried out on the data for Serial Positions 14, which accounted for the major part of the subjects' recall. This within-subjects analysis tested for divergencies in recall across the three conditions, and for practice effects in recall from Block 1 stimulus lists to Block 2. A significant effect for conditions was observed $[F(2,32)=4.11$, MSe $=301.17, p<.025$ ], which was due to the worse recall for the synonym control condition (see Figure 2). There was also a reliable interaction of Condition by Serial Position $[\mathrm{F}(6,96)=4.88, \quad \mathrm{MSe}=109.31$, $\mathrm{p}<.0002$ ] . Comparisons made at each serial position, using the Newman-Keuls procedure, located the interaction at Serial Position 2, with better recall performance for the condition with noise suffix compared with the synonym suffix $(p<.05)$ and the synonym control suffix $(p<.01)$. There were no-differences in recall performance at the remaining three serial positions. Recall performance improves, as expected, from the first to the second block of stimulus lists presented $[F(1,16)=7.12, \mathrm{MSe}=927.73, \mathrm{p}<.01]$. The improvement was uniform across all three conditions and there was no interaction with conditions, nor with any serial position $(p>.20)$. This was the extent for effects across the first four serial positions. Recall performance from Block 1 to Block 2 was also compared with a Wilcoxon test at Serial Position 8, and some improvement $(\mathrm{p}<.05)$ for the synonym condition was noted.

\section{Discussion}

The magnitude of the recall deficit caused by the verbal suffix was interpreted as a measure of the extent to which subjects relied on sensory acoustic information for target word recall. Yet, if this interpretation was correct in placing the burden of the effect on the displacement of precategorical acoustic traces (Crowder \& Morton, 1969; Morton, 1970), then the diminished suffix effect in the synonym condition also demonstrated that subjects did not rely exclusively on this acoustic information, but resorted to an alternative source of recall information when the acoustic trace was no longer available. The effect showed furthermore that a meaningful association between the target word and the suffix word promoted better recall. In this finding, both experiments agreed.

The synonym association reduced suffix interference because the two words, target and suffix, were processed at a semantic level. In this respect, the data were compatible with previous findings (Salter, 1975; Salter, Springer, \& Bolton, 1976) which showed similar coding for the final recall item, and which supported the proposal that serial recall stemmed from a long-term store (Glanzer, 1972; Morton, 1970). This conclusion was thus at variance with Massaro's (1972) proposal, which located suffix interference in short-term memory. Rather than emphasize a distinction between shortterm and long-term memory stores, epitomized by the modal model (Murdock, 1971), the present authors favored a view which posited factors such as rehearsal and time-in-store as more crucial to recall (Brodie, 1975; Brodie \& Prytulak, 1975). The term "rehearsal" might then be extended from a multistore approach (Baddely \& Patterson, 1971; Morton, 1970) to include a more flexible type coding, such as that subscribed to by Craik and Lockhart (1972) and Lockhart, Craik, and Jacoby (1976).

\section{GENERAL DISCUSSION}

Previous tests of the intrinsic as opposed to the extrinsic properties of the suffix did not provide systematic differences in the size of the suffix effect (Morton et al., 1971, p. 177 and Experiments 5, 6, and 14). However, there were a number of procedural differences between those studies and the present one, of which one was the introduction in the present studies of a new final word into the recall list. Data from the first experiment suggested that awareness of a meaningful association between list word and suffix caused a diversion of attention to the final list item at the cost of recalling the third list item (see also Salter and Osler, in press). Anderson and Craik (1974) similarly interpreted their data to propose that processing capacity was required to maintain information in primary memory and that, when capacity was diverted to a subsidiary task, information in primary memory was lost. The second experiment reported here provided no corroborative evidence for this explanation of redirected attention; the first four words for the lists in the synonym condition were better recalled than were those in the nonassociative lists (see Figure 2). Furthermore, in the present experiment, the heterogeneity of the new words was probably less obtrusive because words for the stimulus lists were recruited from a fairly large word pool. The present authors, therefore, passed over a hypothesis based on redirected attention as an explanation of the diminished suffix effect in the synonym condition in favor of a process in which words were registered autonomously against their permanent representations (Anderson \& Bower, 1973; Morton, 1970). Conrad's (1974) results supported this view by showing that subjects were unaware of the activation pattern created by input words. The recall probability of the target word with a synonym suffix could therefore result from two separate factors: extrinsic interference with the acoustic attributes of the target word, and intrinsic facilitation in its recall because the two words were meaningfully associated. Meyer, Schvaneveldt, and Ruddy (1975) described how such facilitation might occur. 
Meyer et al.'s (1975) proposal of spreading excitation included two basic assumptions, which were similar to ones that other investigators have adopted (Collins \& Quillian, 1970; Loftus, 1973; Morton, 1969; Norman, 1968; Rumelhart, Lindsay, \& Norman, 1972). Their first assumption stated that words were stored at distinct "locations" in lexical memory and that their organization was semantic, so that, in some sense, associated words were relatively closer together than were nonassociated words. Their model further assumed that accessing information from a memory location produced residual neural activity that spread to other nearby locations. Facilitation effects of the kind described by the Meyer et al. (1975) model, and observed in the present study, have also been reported by Warren (1972, 1974).

According to this model, the lexical location of the target word was activated twice during list presentation with a synonym suffix, and it was this secondary activation which boosted subsequent recall. The associated suffix thus operated at two coding levels, at least, to produce its "paradoxical effect," because it interfered with the sensory coding of the target word while reactivating that word's representation in lexical memory. A similar effect, which has been observed with visual backward masking (Coltheart \& Grieve, Note 1), suggested that the paradoxical effect reported here was a phenomenon that characterized all sequential encoding processes for associated words. Returning to the stimulus suffix, the next question that arose was to assess the extent of the contribution of precategorical processes to the suffix effect. This evidence of more extensive encoding provoked an alternative interpretation to the previous one which emphasized storage at a precategorical acoustic level; the suffix effect occurred because the suffix blocked more extensive coding and rehearsal processes, which facilitated recall, rather than displacing acoustic information from a store which was functionally separate. This change in the interpretation of the effect represented a small, but fairly crucial, alteration to its understanding.

\section{REFERENCE NOTE}

1. Coltheart, M., \& Grieve, L. The organization of word recognition. Paper given at the British Psychological Society Meeting, December 1, 1973.

\section{REFERENCES}

Anderson, C. M. B., \& Craik, F. I. M. The effect of a concurrent task on recall from primary memory. Journal of Verbal Learning and Verbal Behavior, 1974, 13, 107-113.

ANDERSON, J. R., \& BOWER, G. H. Human associative memory. Washington, D.C: Winston, 1973.

Baddeley, A. D., \& Patterson, $K$. The relationship between long-term and short-term memory. British Medical Bulletin, 1971, 27, 237-242.

Brodie, D. A. Free recall measures of short-term store: Are rehearsal and order of recall data necessary? Memory \& Cognition, 1975, 3, 653-662.

Brodie, D. A., \& Prytulak, L. S. Free recall curves: Nothing but rehearsing some items more or recalling them sooner? Journal of Verbal Learning and Verbal Behavior, 1975, 14, 549-563.

Collins, A. M. \& Quillian, M. R. Facilitating retrieval from semantic memory: The effect of repeating part of an inference. In A. F. Sanders (Ed.), Attention and performance HI. Amsterdam: North Holland, 1970.

Conrad, C. Context effects in sentence comprehension: A study of the subjective lexicon. Memory \& Cognition, 1974, 2, 130-138.

Craik, F. I. M., \& Lockhart, B. S. Levels of processing: A framework for memory research. Journal of Verbal Leaming and Verbal Behavior, 1972, 11, 671-684.

Crowder, R. G., \& Morton, J. Precategorical acoustic storage (PAS). Perception \& Psychophysics, 1969, 5. 365-373.

GLANZER, M. Storage mechanisms in recall. In G. H. Bower (Ed.), The psychology of learning and motivation. New York: Academic Press, 1972.

Kahneman, D. Attention and effort. Englewood Cliffs, N.J; Prentice-Hall, 1973.

KuČerA, H., \& Francis, W. N. Computational analysis of present-day American English. Providence, R.I: Brown University Press, 1967.

Lockhart, R. S., Craik, F. I. M., \& Jacoby, L. Depth of processing, recognition and recall. In J. Brown (Ed.) Recall and recognition. New York: Wiley, 1976.

LofTus, E. F. Activation of semantic memory. American Journal of Psychology, 1973, 86, 331-337.

Massaro, D. W. Preperceptual images, processing time, and perceptual units in auditory perception. Psychological Review, 1972, 79, 124-145.

Meyer, D. E., Schvaneveldt, R. W., \& Ruddy, M. G. Loci of contextual effects on visual word-recognition. In P. M. A. Rabbitt \& S. Dornic (Eds.) Attention and pertormance $V$. London: Academic Press, 1975.

MORTON, J. The interaction of information in word recognition. Psychological Review, 1969, 76, 165-178.

Morton, J. A functional model for memory. In D. A. Norman (Ed.), Models of human memory. New York: Academic Press, 1970.

Morton, J., Crowder, R. G., \& Prussin, H. A. Experiments with the stimulus suffix effect. Journal of Experimental Psychology Monograph, 1971, 91, 169-190.

MuRDocs, B. B., JR. Short-term memory. In G. Bower (Ed.), The psychology of learning and motivation (Vol. 5). New York: Academic Press, 1971.

NoRMAN, D. A. Toward a theory of memory and attention. Psychological Review, 1968, 75, 522-536.

Rumelhart, D. E., Lindsay, P. H., \& Norman, D. A. A process model for long-term memory. In E. Tulving \& W. Donaldson (Eds.), Organization and memory. New York: Academic Press, 1972.

Salter, D. Maintaining recency despite a stimulus suffix. Quarterly Journal of Experimental Psychology, 1975, 27, 433-443.

Salter, D., Springer, G., \& Bolton, L. Semantic coding versus the stimulus suffix. The British Journal of Psychology, $1976,67,339-351$.

Salter, D., \& Osler, J. Residual effects in recall after a stimulus suffix. The British Journal of Psychology, 68, in press.

WARREN, R. E. Stimulus encoding and memory. Journal of Experimental Psychology, 1972, 94, 90-100.

WARREN, R. E. Association, directionality, and stimulus encoding. Journal of Experimental Psychology, 1974, 102, 151-158. 
APPENDLX

Target Recall Words With the Associated and the Nonassociated Stimulus Suffix Words in Experiment 2

\begin{tabular}{|c|c|c|c|c|c|c|c|c|c|c|c|c|c|}
\hline \multirow[b]{2}{*}{1} & \multicolumn{2}{|c|}{ Target } & \multicolumn{2}{|c|}{ Synonym } & \multicolumn{2}{|c|}{ Control } & & \multicolumn{2}{|c|}{ Target } & \multicolumn{2}{|c|}{ Synonym } & \multicolumn{2}{|c|}{ Control } \\
\hline & JUST & 872 & FAIR & 77 & EACH & 77 & 11 & CLOSE & 234 & TIGHT & 28 & DRIED & 28 \\
\hline 2 & NEW & 1635 & FRESH & 82 & ROUND & 81 & 12 & STOUT & 3 & PLUMP & 4 & NUMB & 4 \\
\hline 3 & DARK & 185 & BLACK & 203 & HARD & 202 & 13 & WISE & 36 & SAGE & 2 & TERSE & 2 \\
\hline 4 & FALL & 147 & DROP & 59 & TASTE & 59 & 14 & WILD & 56 & FREE & 260 & REAL & 260 \\
\hline 5 & STRIFE & 6 & WAR & 464 & FACT & 447 & 15 & SHAM & 1 & FAKE & 10 & BLEAK & 10 \\
\hline 6 & HEAT & 97 & WARM & 67 & SIT & 67 & 16 & DREAD & 9 & FEAR & 127 & NOTE & 127 \\
\hline 7 & RUIN & 14 & LOSS & 86 & SHAPE & 85 & 17 & THROW & 42 & PITCH & 22 & BID & 22 \\
\hline 8 & SOFT & 61 & WEAK & 32 & CURT & 32 & 18 & WET & 53 & MOIST & 11 & PROMPT & Г 11 \\
\hline 9 & CALM & 35 & SMOOTH & 42 & RARE & 41 & 19 & BIG & 360 & HUGE & 9 & DENSE & 9 \\
\hline 10 & WRONG & 129 & FALSE & 29 & GAY & 30 & 20 & NIP & 3 & PINCH & 6 & STINT & 6 \\
\hline
\end{tabular}

Note-The figures are frequency ratings taken from Kučera and Francis (1967).

(Received for publication July 20, 1976;

revision received November $23,1976$. 